\title{
OBSERVATION OF OVULATION IN MACACA FASCICULARIS
}

\author{
J. M. R. RAWSON AND W. R. DUKELOW \\ Endocrine Research Unit, Michigan State University, \\ East Lansing, Michigan 48823, U.S.A.
}

(Received 22nd February 1973)

\begin{abstract}
Summary. Laparoscopic observation of the ovaries of seventeen adult regularly cycling Macaca fascicularis was made during their menstrual cycles at the optimal time for detecting follicular development. Preovulatory morphology, follicular rupture and immediate postovulatory morphology were noted and photographed. Data are presented correlating the duration of the follicular phase and the luteal phase with that of the total cycle.
\end{abstract}

Recent developments in laparoscopy have facilitated the observation and photography of the non-human primate reproductive organs in vivo. Reports have described laparoscopic observations of follicular morphology in Macaca fascicularis and depicted follicular development before and after ovulation (Jewett \& Dukelow, 1972).

The objectives of the present study were to view the moment of ovulation, to determine the postovulatory relationships between the ovary and egg mass, and to characterize ovulation in consecutive cycles of the same animal. Portions of this work were included in a preliminary report (Dukelow \& Rawson, 1972).

Seventeen adult Macaca fascicularis, which had been held in captivity for at at least 5 years, were used. These animals were among the same group used in the studies of Jewett and his co-workers which have been previously mentioned.

The technique of laparoscopy used in this study has previously been described (Dukelow, Jarosz, Jewett \& Harrison, 1971). Basically, it involves observation with a fibre optic paediatric laparoscope under Sernylan immobilization (Parke-Davis Co.), with a $\mathrm{CO}_{2}$-produced pneumoperitoneum. Examinations were carried out on Days 12 to 16 of the menstrual cycle depending on the mean duration of the previous six cycles for any individual animal. When ovulation was observed laparoscopically, a laparotomy was performed and the cumulus mass was recovered from the ovarian surface.

The mean duration of 115 complete cycles of the seventeen macaques was $30 \cdot 8 \pm 1 \cdot 0$ days. Seventy-eight ovulations occurred of which thirty-eight $(48.7 \%)$ were on the left ovary and forty $(51.3 \%)$ were on the right. In nineteen examinations, the time of ovulation could be determined within a 24-hr period. The mean duration of the follicular phase was $14 \cdot 1 \pm 1 \cdot 1$ days with a range of 
12.5 to 16 . The mean duration of the luteal phase was $15.6 \pm 1.8$ days with a 10.5- to 18.5-day range.

Table 1. Ovulation characteristics of macaques in different cycles within the same animal

\begin{tabular}{|c|c|c|c|c|c|}
\hline $\begin{array}{c}\text { Female } \\
\text { no. }\end{array}$ & $\begin{array}{l}\text { Duration } \\
\text { of cycle* }\end{array}$ & Ovulation $\dagger$ & $\begin{array}{c}\text { Side of } \\
\text { ovulation }\end{array}$ & $\begin{array}{l}\text { Duration of } \\
\text { this cycle }\end{array}$ & $\begin{array}{l}\text { Luteal } \\
\text { phase }\end{array}$ \\
\hline 40 & $\begin{array}{c}29 \cdot 3 \\
\vdots \\
\vdots \\
\vdots \\
\ddagger\end{array}$ & $\begin{array}{l}15 \cdot 0 \\
12 \cdot 5 \\
12 \cdot 5 \\
14 \cdot 5 \\
14 \cdot 5 \\
15 \cdot 0\end{array}$ & $\begin{array}{l}L \\
R \\
L \\
L \\
R \\
R\end{array}$ & $\begin{array}{l}31 \\
29 \\
29 \\
30 \\
26\end{array}$ & $\begin{array}{l}16.0 \\
16.5 \\
16.5 \\
15.5 \\
11.5\end{array}$ \\
\hline 43 & 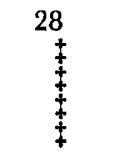 & $\begin{array}{l}12.5 \\
14.5 \\
14.5 \\
14.5 \\
14.5\end{array}$ & $\begin{array}{l}\mathrm{L} \\
\mathrm{L} \\
\mathrm{R} \\
\mathrm{R} \\
\mathbf{L}\end{array}$ & $\begin{array}{l}28 \\
25 \\
32 \\
30\end{array}$ & $\begin{array}{l}15 \cdot 5 \\
10 \cdot 5 \\
17 \cdot 5 \\
15 \cdot 5\end{array}$ \\
\hline 44 & $\underset{\ddagger}{29 \ddagger}$ & $\begin{array}{l}14.5 \\
13.5\end{array}$ & $\begin{array}{l}\mathrm{R} \\
\mathrm{L}\end{array}$ & 30 & $15 \cdot 5$ \\
\hline 53 & $\begin{array}{c}31 \ddagger \\
+ \\
5 \\
5 \\
5\end{array}$ & $\begin{array}{l}16.0 \\
13.5 \\
13.5 \\
14.5 \\
14.5\end{array}$ & $\begin{array}{l}\mathbf{L} \\
\mathbf{R} \\
\mathbf{R} \\
\mathbf{L} \\
\mathbf{R}\end{array}$ & $\begin{array}{l}30 \\
30 \\
29 \\
31\end{array}$ & $\begin{array}{l}14 \cdot 0 \\
16 \cdot 5 \\
15 \cdot 5 \\
16 \cdot 5\end{array}$ \\
\hline 54 & $\begin{array}{c}33 \ddagger \\
\ddagger\end{array}$ & $\begin{array}{l}15 \cdot 0 \\
16 \cdot 5\end{array}$ & $\begin{array}{l}\mathbf{R} \\
\mathbf{R}\end{array}$ & $\begin{array}{l}31 \\
34\end{array}$ & $\begin{array}{l}16 \cdot 0 \\
17 \cdot 5\end{array}$ \\
\hline
\end{tabular}

* Mean of the six previous cycles.

$\dagger$ Approximate day of ovulation.

Denotes consecutive cycles.

$\S$ Denotes a second series of consecutive cycles.

Table 1 illustrates the relationship between consecutive cycles in five animals. In seven of eleven $(63.6 \%)$ paired cycles, ovulation occurred on opposite ovaries while in the remaining four $(36.4 \%)$, ovulation occurred on the same ovary in both cycles.

\section{EXPLANATION OF PLATE 1}

FIG. 1. An early stage of follicular rupture in a macaque, showing clear follicular fluid protruding from the stigma.

Fig. 2. Following the completion of follicular rupture, the egg mass is seen adhering tightly to the ovarian surface.

Fig. 3. Characteristic single stigma type of preovulatory follicie.

Fig. 4. Luteal scars from three previous ovulations.

Fig. 5. Consecutive ovulations on the same ovary. The arrow points to the preovulatory follicle.

FiG. 6. Multiple luteal scars on the ovary of a unilaterally ovariectomized macaque.

Fig. 7. A preovulatory follicle on the same ovary as that shown in Fig. 6.

Fig. 8. A follicle on the left ovary of a macaque (see Fig. 9).

Fig. 9. A follicle on the right ovary of the same macaque as in Fig. 8 and during the same cycle.

Fig. 10. A follicle showing the complex vascular pattern. 
|'। \1।:
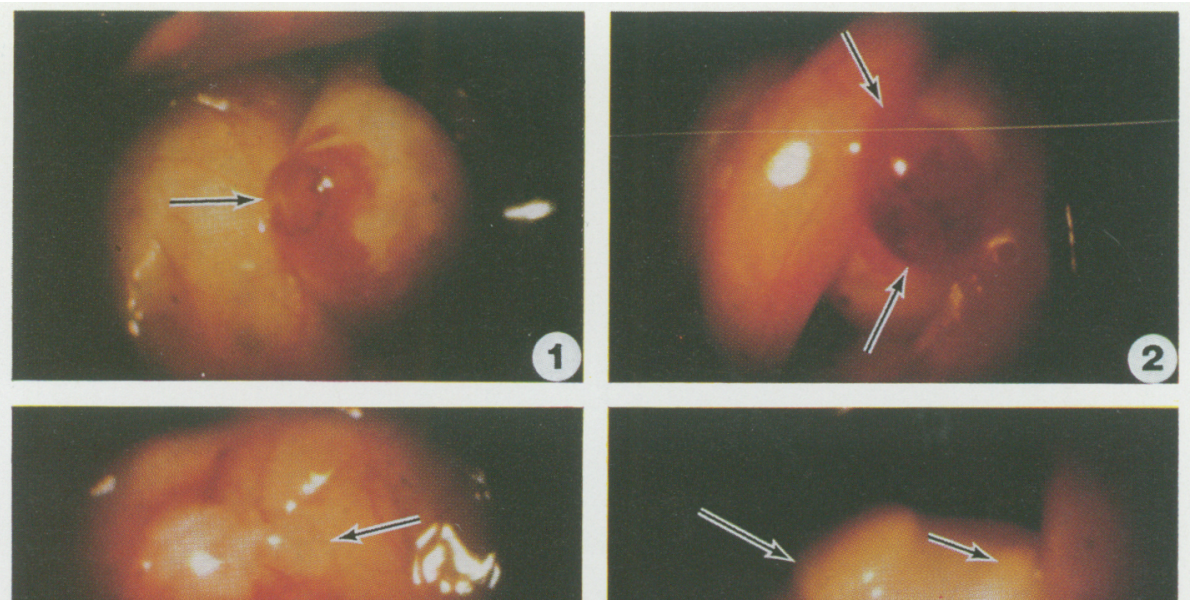

3
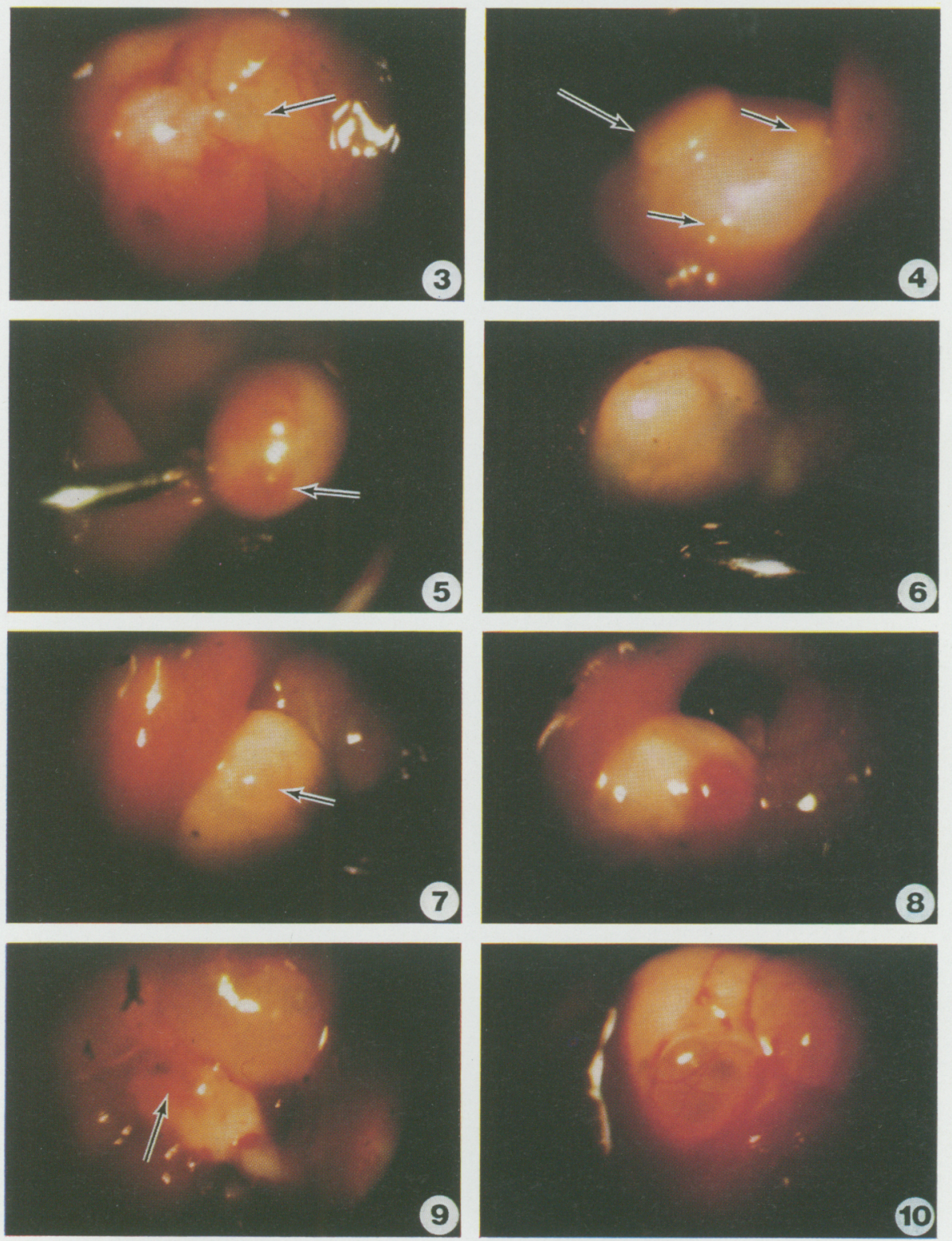
The moment of follicular rupture was observed and photographed in three animals (Pl. 1, Figs 1 and 2). Clear follicular fluid was first seen protruding from the stigma (Pl. 1, Fig. 1). Immediately after ovulation, the cumulus mass adhered to the ovary (PI. 1, Fig. 2). Follicular rupture and release of the ovum took place in approximately $30 \mathrm{sec}$. At laparotomy, the cumulus mass could be stretched $1.5 \mathrm{~cm}$ before it separated from the ovary. Under microscopic examination, the ovum was observed within the mass.

The characteristic preovulatory follicle in the macaque shown in P1. 1, Fig. 3 had a large, protruding stigma as ovulation approached. The ovary depicted in Pl. 1, Fig. 4 had evident luteal scars from three previous ovulations. In Pl. 1, Fig. 5, a preovulatory follicle is seen in close proximity to the CL of the previous cycle. In one female (Pl. 1, Figs 6 and 7), one ovary was removed without affecting the regular ovulatory pattern. Twin follicles were a rarity. We have never seen twin ovulations on the same ovary and only twice have observed separate follicles on opposite ovaries during one cycle (Pl. 1, Figs 8 and 9). The preovulatory follicle was usually of the single stigma type (P1. 1, Fig. 3), or the hemispheric type described by Jewett \& Dukelow (1972). Occasionally, the vascular pattern produced a follicle with polystigmata (Pl. 1, Fig. 10).

The observations of follicular development confirm earlier reports on the progressive morphological changes, and add details of the changes involved at the moment of ovulation. The total time required for ovum expulsion was short, $30 \mathrm{sec}$, which is approximately the time reported by Blandau (1955) for ovulation in the rat when the ovum was located in the base of the follicle before the start of ovulation.

The adherence of the egg mass to the ovarian surface and the strength of this adhesion may be of importance in the mechanism of the transfer of the ovum to the oviduct and one can speculate that a sweeping motion of the fimbria over the ovarian surface occurs in primates as in other species showing this characteristic, i.e. the rabbit.

Laparoscopic examination of the ovaries of Macaca fascicularis before ovulation confirms the previous finding in related macaques that there is considerable variation in the appearance of the follicles (Betteridge, Kelly \& Marston, 1970), and particularly of the stigma (Johansson, Neil \& Knobil, 1968), but still allows a prediction to be made of the time of ovulation which is based primarily on the appearance of the stigma and its associated vasculature. Variations of ovarian morphology in the macaque, including twin follicles, have been demonstrated.

There was no indication of alternation of ovulation between ovaries. In fact, the data on paired cycles and on the longer consecutive series indicate a random selection of the follicular site.

This project was supported by USPHS Grant No. 5-PO6-RR 00366, and NIH Research Career Development Award No. 1-K4-HD35, 306. Special thanks are expressed to Dr Seiichiro Fujimoto for his valuable assistance during surgical recovery of the ova. The paper has been approved by the Director, Michigan Agricultural Experiment Station, Journal Series No. 6288. 


\section{REFERENCES}

Brandau, R. J. (1955) Ovulation in the rat. $16 \mathrm{~mm}$ film, University of Washington Film Service, Seattle, Washington.

Betteridge, K. J., Kelly, W. A. \& Marston, J. H. (1970) Morphology of the rhesus monkey ovary near the time of ovulation. F. Reprod. Fert. 22, 453.

Duxelow, W. R., Jarosz, S. J., Jewetr, D. A. \& Harrison, R. M. (1971) Laparoscopic examination of the ovaries in goats and primates. Lab. Anim. Sci. 21, 594.

Dukelow, W. R. \& Rawson, J. M. R. (1972) Comparative ovulation in nonhuman primates. Fedn Proc. Fedn Am. Socs exp. Biol. 31, 277.

JEWETt, D. A. \& DukeLow, W. R. (1972) Serial observations of follicular morphology near ovulation in Macaca fascicularis. 7. Reprod. Fert. 31, 287.

Johansson, E. D. G., NeIL, J. D. \& KNOBIL, E. (1968) Peri-ovulatory progesterone concentration in the peripheral plasma of the rhesus monkey with a methodologic note on the detection of ovulation. Endocrinology, 82, 143. 